http://dx.doi.org/10.35381/racji.v6i10.1150

\title{
La Corte Constitucional como garante del Principio de Independencia Judicial en Ecuador
}

\section{The Constitutional Court as guarantor of the Principle of Judicial Independence in Ecuador}

María José Zapata-Fajardo dq@uniandes.edu.ec

Universidad Regional Autónoma de los Andes, Quevedo

Ecuador

https://orcid.org/0000-0002-0567-0236

Orlando Iván Ronquillo-Riera uq.orlandoronquillo@uniandes.edu.ec Universidad Regional Autónoma de los Andes, Quevedo Ecuador https://orcid.org/0000-0001-6020-7255

Rously Eedyah Atencio-González

uq.rouslyatenio@uniandes.edu.ec

Universidad Regional Autónoma de los Andes, Quevedo Ecuador

https://orcid.org/0000-0001-6845-1631

Recepción: 01 de septiembre 2020

Revisado: 15 de octubre 2020

Aprobación: 18 de diciembre 2020

Publicación: 01 de enero 2021 


\section{RESUMEN}

El artículo tiene como propósito analizar la actuación Jurisdiccional de la Corte Constitucional dentro de la Sentencia 3-19-CN/20, en la cual dentro de un proceso de consulta de norma efectuado por un órgano jurisdiccional de instancia, realiza una interpretación conforme principalmente, de la figura de error enexcusable. Por todo ello se planteó como objetivo general analizar la actuación Jurisdiccional de la Corte Constitucional dentro de la Sentencia 3-19-CN/20, en la administracion de justicia y vulneración del principio de Independencia Judicial en Ecuador. Bajo el enfoque cualitativo y metodológicamente desde un tipo descriptivo-documental, mediante un diseño bibliográfico, permitió la revisión analítica conformada por: leyes, documentos jurídicos, artículos y trabajos de investigación, escrutándose a través del método analítico - sintético y análisis de contenido jurídico. Se observa que un órgano jurisdiccional es quien debe declarar la existencia de error inexcusable, dolo o negligencia en la tramitación de causas judiciales, lo contrario supondría irrespeto al principio de independencia judicial.

Descriptores: Independencia judicial; corte constitucional; principio. (Palabras tomadas del Tesauro UNESCO).

\section{SUMMARY}

This article aims to analyze the Jurisdictional action of the Constitutional Court within Sentence 3-19-CN / 20, in which within a process of consultation of the norm carried out by a judicial body of instance, it makes an interpretation according mainly of the figure of an excusable error. Therefore, the general objective was to analyze the Jurisdictional action of the Constitutional Court within Sentence 3-19-CN / 20, in the administration of justice and violation of the principle of Judicial Independence in Ecuador. Under the qualitative and methodological approach from a descriptivedocumentary type, through a bibliographic design, it allowed the analytical review made up of: laws, legal documents, articles and research papers, scrutinizing it through the analytical-synthetic method and analysis of legal content. It is observed that a court is the one who must declare the existence of inexcusable error, fraud or negligence in the processing of legal cases, otherwise it would imply disrespect for the principle of judicial independence.

Descriptors: Judicial independence; constitutional court; principle. (Words from UNESCO Thesaurus). 


\section{INTRODUCCIÓN}

Al referirse al principio de separación de poderes, la doctrina lo considera la pieza fundamental dentro de las democracias modernas, principio que tendría su nacimiento con la Constitución de los Estados Unidos de 1787 y que sería consolidado más tarde en la Declaración de Derechos del Hombre de 1789 de Francia, pues en el artículo 16 establecía que: "Una sociedad en la que la garantía de los derechos no está asegurada, ni la separación de poderes determinada, no tiene constitución". (Asamblea Nacional de Francia, 1789)

Profundamente unido con la separación de poderes está el principio de independencia judicial, establecido en el artículo 168 numeral 1 de la Constitución de la República del Ecuador del año 2008, como se muestra a continuación: Los órganos de la Función Judicial gozarán de independencia interna y externa. Toda violación a este principio conllevará responsabilidad administrativa, civil y penal de acuerdo con la ley, así mismo en correspondencia con el Código Orgánico de la Función Judicial (2009) en su artículo 8 inciso segundo: "Ninguna Función, órgano o autoridad del Estado podrá interferir en el ejercicio de los deberes y atribuciones de la Función Judicial" Autores como (Grijalva, 2012) manifiestan que "La noción de independencia judicial es siempre discutible, siempre problemática pues cualquier concepto de independencia está ligado a la forma como veamos las relaciones entre derecho y política". Clásicamente en el Ecuador la independencia judicial como principio ha estado marcadamente influenciada y a la vez disminuida por la injerencia política latente en todos los estamentos estatales que ven en la justicia un botín por medio del cual se puede llegar a la consecución de objetivos políticos, estando presente la impunidad y el irrespeto al debido proceso y tutela judicial efectiva.

Por su parte, la Organización de las Naciones Unidas refiriéndose dentro de los Principios básicos relativos a la independencia de la judicatura en 1985, estableció que "La independencia de la judicatura será garantizada por el Estado y proclamada por la Constitución o la legislación del país". En este sentido, las democracias modernas contemplan en sus constituciones que los poderes del Estado son independientes unos de otros, sin embargo, en la práctica no es así, la presión política 
o mediática especialmente en el ámbito de la administración de justicia es latente.

En la presente investigación se aborda, la afectación al principio de independencia judicial que durante muchos años se vio mermada por parte del Consejo de la Judicatura, al establecer cientos de sumarios administrativos contra operadores de justicia, bajo la figura de "error inexcusable, fuerza o dolo" contemplados a manera de sanción en el (Código Orgánico de la Función Judicial, 2009) donde evidentemente se demuestra la lejanía, a lo que se encuentra normado.

Es de actualidad el tema investigado, ya que, en el pasado mes de julio del año 2020, la Corte Constitucional en una decisión histórica decide pronunciarse respecto de la forma como se venía sancionando a jueces y a conocedores del derecho como fiscales y defensores públicos, con una figura jurídica que a criterio de muchos constituye violación al principio de legalidad, al no determinar con exactitud las conductas en el artículo 109 numeral 7 del Código Orgánico de la Función Judicial. (Código Orgánico de la Función Judicial, 2009)

Por otra parte, los Principios básicos de la ONU establecen que son los Estados quienes deben garantizar la independencia del poder judicial y que la misma debe estar contenida en la Constitución o legislación de los países. La Corte Interamericana ha señalado que el objetivo de la protección de la independencia judicial "radica en evitar que el sistema judicial en general y sus integrantes en particular se vean sometidos a posibles restricciones indebidas en el ejercicio de su función por parte de órganos ajenos al Poder Judicial o incluso por parte de aquellos magistrados que ejercen funciones de revisión o apelación". En este contexto, surgen dos dimensiones de la independencia judicial: la independencia institucional y la individual. (Centro por la Justicia y el Derecho Internacional, 2019:8)

Es de trascendental importancia investigar acerca de uno de los principales principios en materia judicial, como lo es el principio de independencia, mismo que goza de rango constitucional y legal, pero que en poca medida se cumple dentro del sistema de Administración de justicia. Además, se pone en evidencia el rol preponderante de la Corte Constitucional, misma que como legislador negativo, extrae incompatibilidades normativas dentro de la legislación ecuatoriana, convirtiéndose por 
excelencia en el defensor de la Constitución.

En este sentido, la figura del error inexcusable, ha traído consecuencias catastróficas para los operadores de justicia, pues ha significado una camisa de fuerza en el deber de administrar justicia. Mediante esta figura, se han destituido a muchos jueces, pues el Consejo de la Judicatura, desbordando sus competencias ha ejercido control jurisdiccional al revisar fallos emitidos por jueces, situación sin lugar a dudas inconstitucional, pues únicamente se puede efectuar este control, por el juez superior en apelación o dentro de cualquier otro recurso, de conformidad con el principio de doble conforme, establecido en el artículo 76, numeral 7, literal m de la Constitución. (Constitución de la República del Ecuador, 2008).

Por otra parte, en los artículos 1 a 7 de los Principios Básicos de las Naciones Unidas Relativos a la Independencia de la Judicatura se enuncian los elementos de la independencia de la judicatura. La premisa fundamental es que la independencia de la judicatura será garantizada por el Estado y proclamada por la Constitución o la legislación del país. Los jueces resolverán los asuntos de los que conozcan con imparcialidad, basándose en los hechos y en consonancia con el derecho, sin restricción alguna y sin influencias, alicientes, presiones, amenazas o intromisiones indebidas. Los propios tribunales deberán decidir si una cuestión que les haya sido sometida está dentro de la competencia que les haya atribuido la ley. No se efectuarán intromisiones indebidas o injustificadas en el proceso judicial, incluso en lo que respecta a los casos asignados a los jueces, por parte de los otros poderes del Estado (legislativo y ejecutivo). (Oficina de la Naciones Unidas Contra la Droga y el Delito, 2010). Por todo ello se hace necesario analizar la actuación Jurisdiccional de la Corte Constitucional dentro de la Sentencia 3-19-CN/20, en la administracion de justicia y vulneracion del principio de Independencia Judicial en Ecuador.

\section{MÉTODO}

La presente investigación se adhiere al enfoque cualitativo que es aquel que, se orienta al estudio de métodos de recolección de datos y de observaciones para descubrir de manera discursiva categorías conceptuales. Donde a partir de esa 
revisión y el estudio de la realidad normativa y social se logra inferir de manera reflexivas por parte de los investigadores, construyendo así una idea bien sustentada de la realidad. Se trabajó mediante un diseño bibliográfico, mediante un análisis de una población conformada por documentos jurídicos, leyes, artículos escrutándose mediante un método analítico-sintético y el análisis del contenido, y todas las ideas más relevantes sobre el tema en cuestión lo que permitió componer una síntesis teórica sobre el principio de independencia judicial en la legislación ecuatoriana.

Por otro lado, en relación a esto se efectuó un análisis documental de la postura de organismos internacionales y normativo donde a través de este método de nivel empírico del conocimiento, surge una orientación científica dentro de la investigación, donde se analizó, la Sentencia 3-19-CN/20, así como Jurisprudencia Nacional e Internacional respecto al principio de Independencia Judicial.

\section{RESULTADOS}

El sistema de control constitucional, adoptado por el Ecuador en su actual Constitución (2008) es el concentrado, puesto que solamente la Corte Constitucional puede efectuar control e interpretación de la Norma Suprema, no así de la ley donde el intérprete autentico es el legislador. Por ello se entiende, que únicamente la Corte Constitucional, puede llevar a cabo este control de fondo y de forma; dentro del control concentrado, está el abstracto que se refiere a: convocatorias de consultas populares, control de constitucionalidad de estados de excepción, Tratados Internacionales, control de reforma constitucional, entre otros, determinados en el artículo 75 de la (Ley Orgánica de Garantías Jurisdiccionales y Control Constitucional, 2009)

A criterio de los investigadores y para efectos de la presente investigación, el tipo de control utilizado por parte de la Corte Constitucional, para suplir las omisiones administrativas y legales efectuadas por parte del Consejo de la Judicatura es el control concreto, también llamado consulta judicial de norma, que se refiere únicamente a un caso a diferencia del abstracto; donde la Carta Magna, lo recoge de la siguiente manera:

Artículo 428.- Cuando una jueza o juez, de oficio o a petición de parte, considere que una norma jurídica es contraria a la Constitución o a los 
instrumentos internacionales de derechos humanos que establezcan derechos más favorables que los reconocidos en la Constitución, suspenderá la tramitación de la causa y remitirá en consulta el expediente a la Corte Constitucional, que, en un plazo no mayor a cuarenta y cinco días, resolverá sobre la constitucionalidad de la norma. Si transcurrido el plazo previsto la Corte no se pronuncia, el perjudicado podrá interponer la acción correspondiente. (Constitución de la República del Ecuador, 2008)

En cuanto a la revisión de norma, efectuada en esta investigación, dentro de la (Sentencia 3-19-CN/20, 2020), dictada el 29 de julio del 2020, en el dictamen de la misma, la Corte ha esgrimido que "es frecuente hallar en todas las legislaciones normas disciplinarias con tipificaciones sancionatorias abiertas", en alusión a que por error inexcusable, se puede entender cualquier cosa, criterio compartido por (Álvarez \& Ocampo, 2019) quienes señalan, que no se explicita en la legislación, el concepto de error inexcusable.

En el proceso de consulta de norma, ésta debe estar justificada y estar debidamente motivada, como toda resolución emitida por los órganos del poder público, tal como lo muestra la jurisprudencia constitucional establecida en la (Sentencia № $001-13-$ SCN-CC, 2013) la consulta "debe ser motivada y justificar claramente que no existe posibilidad de recurrir a una interpretación conforme del enunciado normativo a la luz de los dispuesto en la Constitución".

En relación con esto, la Corte Constitucional, ha establecido que para que se determine el "error inexcusable, dolo y culpa es necesario que exista tal declaración por un órgano jurisdiccional, y sólo allí el Consejo de la Judicatura, podrá emitir una sanción disciplinaria, pues no puede un ente administrativo, revisar decisiones judiciales, ya que esto atenta claramente contra el principio de independencia judicial interna. Puntualizando que, en materia disciplinaria, distinto a lo que predomina en materia penal, se sanciona la conducta y no el resultado.

Por otro lado, los operadores de justica, fiscales o defensores públicos pueden tener criterios divergentes, dentro de sus respectivas actuaciones, pero ello no implica incurrir en la figura de error inexcusable, pues el juez, fiscal o defensor no es infalible, y en el caso de error, existe el recurso de apelación respectivo dentro de un proceso; agregando que error inexcusable, debería ser, el aplicar una norma derogada o una 
ley inexistente, pues la diversidad de criterios no configuraría el error inexcusable. Dentro de ese marco, la Organización de Estados Americanos, a través de la Comisión Interamericana de Derechos Humanos en el 2013, en su recomendación 248, indica la Comisión considera que la existencia de organismos independientes encargados de la administración y gobierno del poder judicial, constituyen una buena práctica para fortalecer la independencia en los Estados y por tanto, insta a los Estados en donde no existan, a crearlos y dotarlos de las garantías que posibiliten su pleno actuar independiente en cada una de las funciones que tienen asignadas en los términos señalados por el derecho internacional y los estándares indicados por la Comisión en el presente informe. La independencia de justicia, deberá garantizar la buena actuación de los responsables de su administración, sin perjuicio de las normas. Por lo tanto, es viable lo planteado en el principio 16 de los Principios Básicos Relativos a la Independencia de la Judicatura se dispone que los jueces gocen de inmunidad personal con respecto a las acciones civiles derivadas de acciones $u$ omisiones indebidas cometidas en el ejercicio de sus funciones judiciales. La inmunidad judicial que exime a los jueces de responsabilidad constituye un elemento de la independencia judicial ya que permite a los jueces hacer su trabajo sin miedo a acciones civiles o penales injustificadas. Esa inmunidad no tiene por qué ser total, puede estar sujeta a determinadas restricciones como, por ejemplo, que los jueces deban actuar conforme al derecho, con la debida prudencia y buena fe. La responsabilidad personal de los jueces con respecto a las acciones civiles debe considerarse como una responsabilidad diferente de la gubernamental en el caso de errores graves o conductas ilícitas por parte de sus jueces. Una persona que se haya visto perjudicada a raíz de alguno de estos últimos casos tendrá derecho a querellar contra el Estado por daños y perjuicios. Del mismo modo, la inmunidad evocada en el mencionado principio 16 no excluye la aplicación de medidas disciplinarias contra un juez que haya actuado de manera indebida o por incumplimiento de sus obligaciones. (Oficina de las Naciones Unidas Contra la Droga y el Delito, 2010) Respecto de este tema la Corte Interamericana ya se ha pronunciado en varias ocasiones, así por ejemplo en el caso (Apitz Barbera y otros Vs Venezuela, 2008) se 
establece que: Previo a la destitución de los jueces, era necesario que la Comisión de Funcionamiento y Reestructuración del Sistema Judicial (CFRSJ) realice un análisis diferenciado del error judicial inexcusable, que debía contener:

(i) El análisis de la idoneidad de los jueces para el ejercicio de su cargo,

(ii) Razones sobre la gravedad de la falta y

(iii) Un análisis autónomo y suficientemente motivado de los alegatos de defensa de los jueces destituidos.

En virtud de que no han concurrido estos tres requisitos, la Corte Interamericana de Derechos Humanos (Corte IDH) consideró que el Estado incumplió su deber de motivar la sanción de destitución, violando las debidas garantías establecidas en el artículo 8.1 de la Convención Americana.

Situación que hoy, la Corte Constitucional confirma, afirmando que un órgano administrativo no puede declarar dolo, manifiesta negligencia error inexcusable, sin antes tener una declaración previa por parte de un órgano jurisdiccional, por tanto, esta declaración solo pueden realizarla quienes tienen jurisdicción y conocen la causa por la vía de algún recurso en materia legal, es decir los jueces y tribunales. A través de la (Sentencia 3-19-CN/20, 2020) la Corte Constitucional realizó una interpretación conforme del artículo 109 del Código Orgánico de la Función Judicial (COFJ), además se declara la inconstitucionalidad de la actuación de oficio del Consejo de la Judicatura prevista en el artículo 113 del (Código Orgánico de la Función Judicial, 2009) exclusivamente para la aplicación del artículo 109 numeral 7 del mencionado cuerpo legal. En los casos de que haya denuncia, el Consejo de la Judicatura requerirá, sin emitir un criterio propio, una declaración jurisdiccional previa por parte del juez o tribunal que conoce el recurso, para iniciar el sumario administrativo y, en procesos de única instancia, la declaración jurisdiccional deberá realizarla el juez o tribunal del nivel orgánicamente superior.

De conformidad con la parte resolutiva de la (Sentencia 3-19-CN/20, 2020), si el Consejo de la Judicatura pretende aplicar sanciones en virtud del artículo 109 del (Código Orgánico de la Función Judicial, 2009) Código Orgánico de la Función Judicial, deberá observar lo siguiente: 
1. Referencia de la declaración previa de un juez en el que conste que existe dolo, manifiesta negligencia y error inexcusable.

2. El análisis de la idoneidad de los jueces para el ejercicio de su cargo.

3. Razones sobre la gravedad de la falta disciplinaria.

4. Un análisis motivado sobre los argumentos de la defensa de los funcionarios investigados.

5. Detallar el tipo de sanción proporcional a la infracción.

\section{DISCUSIÓN.}

La intromisión en el sistema de justicia de otros órganos estatales ajenas a la función judicial, perjudican y afectan enormemente al normal funcionamiento del sistema jurisdiccional, el Ecuador ya ha sido condenado por parte de la Corte Interamericana de derechos Humanos, en (Quintana Coello y Otros Vs Ecuador, 2013) se declaró la responsabilidad Ecuador por haber vulnerado derechos reconocidos en la Convención Americana de Derechos Humanos, esto debido a que el Congreso del Ecuador, órgano legislativo de la época destituyó a los jueces de la Corte Suprema de Justicia, sin tener la competencia para aquello, violando de esta forma el principio de separación de poderes.

Similar situación ocurrió con los miembros del Tribunal Constitucional, quienes fueron destituidos antes que los magistrados de la Corte Suprema de Justicia, ya que con la finalidad de evitar el control de constitucionalidad el Congreso Nacional procedió a destituirlos, trayendo consigo otra demanda internacional que también la perdió el estado ecuatoriano ante la Corte Interamericana de Derechos Humanos, el caso (Camba Campos vs Ecuador, 2013), cuyos montos a pagar entre los 2 casos superaron los 13 millones de dólares por concepto de reparación integral.

La Corte Constitucional, al pronunciarse sobre el error inexcusable, ha tomado en cuenta los dos casos anteriores para desarrollar su Jurisprudencia, denotando que las implicaciones legales pueden superar nuestras fronteras; ante aquello es de especial relevancia destacar la importancia que tienen al respecto, al principio de independencia interna y externa del cual goza la función judicial. 
En relación a lo anterior, el hecho de solicitar una declaración previa jurisdiccional, respecto de si se cometió o no error inexcusable, dolo o negligencia por parte de la Corte Constitucional, permite que dentro de un proceso judicial pueda existir injerencia en los fallos dictados por los jueces, puesto que un órgano administrativo como el Consejo de la Judicatura; no puede, ni debe efectuar control jurisdiccional de fallos, puesto que estos pueden ser apelables y su situación puede variar sustancialmente y con ello quedaría solventada cierta inconformidad.

Antes de que entrara en vigencia la disposición de que es necesaria la declaratoria jurisdiccional previa a la sanción, el Consejo de la Judicatura realizó incontables sumarios administrativos contra jueces, todos amparados en la figura de error inexcusable, en la mayoría de casos por inconformidad de los fallos, más que por errores de fondo o de forma en la tramitación de las causas judiciales.

A criterio de (Zaleta, 2001) indica que "sin temor a equivocarnos, los Jueces y Magistrados se equivocan cotidianamente. Ninguno de ellos, en su sano juicio, puede afirmar que jamás ha incurrido en un error judicial, o que en muy pocas ocasiones lo ha cometido". No obstante, una cosa es equivocarse por interpretaciones propias de las normas o de apreciación de hechos subsumibles al caso, y otra muy distinta es el ser destituido de tu cargo como juez por actuaciones jurisdiccionales sujetas a errores y a interpretaciones.

\section{CONCLUSIONES.}

La garantía jurisdiccional de la Constitución -la justicia constitucional- es un elemento del sistema de los medios técnicos que tienen como fin asegurar el ejercicio regular de las funciones estatales. Estas funciones tienen en sí mismas un carácter jurídico: constituyen actos jurídicos. Son actos de creación de Derecho, esto es, de normas jurídicas o actos de ejecución del Derecho creado, es decir, de normas jurídicas vigentes. En consecuencia, tradicionalmente se distinguen las funciones estatales en legislación y ejecución, distinción en que se opone la creación o producción del Derecho a la aplicación del Derecho, considerada esta última como una simple reproducción. (Kelsen,2011:254) 
Con la interpretación constitucional dada respecto de la figura del error inexcusable, se ha quitado una camisa de fuerza que tenían los administradores de justicia al sustanciar procesos judiciales, pues la figura de error inexcusable prevista en el (Código Orgánico de la Función Judicial, 2009) a manera de sanción, afectaba de manera directa al principio de independencia interna de los cuales gozan los jueces en el Ecuador.

La labor de administrar justicia, a criterio de los investigadores y una vez realizadas las inferencias reflexivas de las normas y jurisprudencia consultadas, debe ser independiente, con la finalidad de que la justicia, máximo ideal que tienen el derecho pueda brillar y esclarecer la verdad procesal de los hechos, evitando de esta forma que lo establecido en relación a los principios de independencia judicial, se vea vulnerado.

\section{FINANCIAMIENTO}

No monetario.

\section{AGRADECIMIENTO}

A la Universidad Regional Autónoma de los Andes, Quevedo; por motivar el desarrollo de la Investigación.

\section{REFERENCIAS CONSULTADAS}

Álvarez, W. C., \& Ocampo, A. D. (2019). El error inexcusable en la legislación ecuatoriana. [The inexcusable error in Ecuadorian law]. Universidad y Sociedad. 11(4),436-442. Recuperado de: https://n9.cl/ev5co

Asamblea Nacional Constituyente de la República del Ecuador, (2008). Constitución de la República del Ecuador. [ Montecristi. Registro Oficial 449 de 20-oct-2008. Recuperado de https://n9.cl/sia

Asamblea Nacional Constituyente de la República del Ecuador, (2008). Código Orgánico de la Función Judicial. [Organic Code of Judicial Function]. Registro oficial Suplemento 544 de 09-mar-2009. 
Asamblea Nacional de la República del Ecuador, (2009). Ley Orgánica de garantías Jurisdiccionales y Control Constitucional. [Organic Law on Jurisdictional Guarantees and Constitutional Control] Registro Oficial Suplemento 52 de 22oct-2009.

Asamblea Nacional de Francia. (28 de agosto de 1789). Declaración de derechos del hombre y el ciudadano. [Declaration of human and citizen's rights] Recuperado de: https://n9.cl/7p13u

Caso Camba Campos Vs Ecuador (Corte Interamericana de Derechos Humanos 13 de agosto de 2013).

Caso Quintana Coello y Otros Vs Ecuador (Corte Interamericana de Derechos Humanos 23 de agosto de 2013)

Centro por la Justicia y el Derecho Internacional (2019) Compendio de Estándares Internacionales para la Protección de la Independencia Judicial. [Compendium of International Standards for the Protection of Judicial Independence]. Recuperado de: www.cejil.org

Corte Constitucional del Ecuador, Sentencia № 001-13-SCN-CC. Caso No 0535-12CN (Corte Constitucional del Ecuador. [Constitutional Court of Ecuador] Recuperado de: https://n9.cl/dhg7a 06 de febrero de 2013.

Corte Constitucional del Ecuador, Sentencia No 3-19 CN/20 Caso № 3-19-CN (Error Inexcusable) (Corte Constitucional del Ecuador. [Constitutional Court of Ecuador] Recuperado de: https://n9.cl/97a4 (29 de julio de 2020)

Corte Interamericana de Derechos Humanos [Inter-American Court of Human Rights] Caso Apitz Barbera y otros (Corte Primera de lo Contencioso Administrativo) vs. Venezuela Sentencia de 5 de agosto de 2008 (Excepción preliminar, Fondo, Reparaciones y Costas) recuperado de: https://n9.cl/wyus

Grijalva, A. (2012). Constitucionalismo en Ecuador. [Constitutionalism in Ecuador] Quito: Centro de Estudios y Difusión del Derecho Constitucional.

Naciones Unidas (1948). Declaración Universal de Derechos Humanos. [Universal Declaration of Human Rights]. Recuperado de https://url2.cl/d9qxa

Organización de las Naciones Unidas. (1985). Declaración sobre los Principios Fundamentales de Justicia para las Víctimas de Delitos y del Abuso de Poder. [Statement on the Fundamental Principles of Justice for Victims of Crime and Abuse of Power] Recuperado de: https://n9.cl/pv9vx 
Oficina de las Naciones Unidas Contra la Droga y el Delito (2010). Acceso a justicia Independencia, imparcialidad e integridad de la judicatura. [Access to justice Independence, impartiality and integrity of the judiciary]. Recuperado de: https://n9.cl/8yre9

Kelsen, H. (1994). La garantía jurisdiccional de la Constitución. La Justicia Constitucional. [The jurisdictional guarantee of the Constitution. Constitutional Justice]. IUS ET VERITAS, 5(9), 17-43. Recuperado de: https://n9.cl/9i51

Zaleta, M. M. (2001). El error judicial inexcusable como causa de responsabilidad administrativa. [The inexcusable judicial error as a cause of administrative responsibility]. Suprema Corte de Justicia de la Nación. Recuperado de: https://www.corteidh.or.cr/tablas/20518.pdf 